\title{
Simultaneous Isolation and Enumeration of Virulent Vibrio Cholerae and Vibrio Vulnificus using an Advanced MPN-PCR Method
}

\section{Jae-Hwa Lee}

Pukyong National University

Seul-Ki Park

Pukyong National University

\section{Fazlurrahman Khan}

Pukyong National University

\section{Du-Min Jo}

Pukyong National University

\section{Do-ha Lee}

Pukyong National University

Min-Gyun Kang

Pukyong National University

Young-Mog Kim ( $\nabla$ ymkim@pknu.ac.kr)

Pukyong National University https://orcid.org/0000-0002-2465-8013

\section{Research Article}

Keywords:

Posted Date: June 2nd, 2021

DOI: https://doi.org/10.21203/rs.3.rs-528186/v1

License: (c) (i) This work is licensed under a Creative Commons Attribution 4.0 International License.

Read Full License

Version of Record: A version of this preprint was published at Archives of Microbiology on December 6th, 2021. See the published version at https://doi.org/10.1007/s00203-021-02613-y. 


\section{Abstract}

Vibrio cholerae and Vibrio vulnificus are one of the critical foodborne pathogens that need to be intensively controlled their infection as a result of the intake and distribution of seafood, especially raw oysters. For this reason, various methods have already been developed for the detection and enumeration of these bacteria. The most probable number (MPN)-PCR (polymerase chain reaction) method is commonly used with the selective-differential medium for the efficiency and convenience of cell enumeration. One of the most frequently used for the detection of Vibrio spp. is Thiosulfate-Citrate-Bile salts-Sucrose (TCBS) agar. But this selective-differential medium can fail to distinguish between $V$. cholerae, $V$. vulnificus, and Vibrio alginolyticus. For this reason, the conventional MPN-PCR method with TCBS medium for the detection of Vibrio spp. has a problem that processing PCR to the two-times. This study suggests a simple and minimized detection method using one-time PCR and non- $\mathrm{NaCl}$ Luria-Bertani (LB-0) medium culture. This detection method is based on the difference in salt requirement between $V$. cholerae and $V$. vulnificus. Employing the developed methodology, the simultaneous cell enumeration of $V$. cholerae and $V$. vulnificus can be possible at a low cost. Furthermore, this study proposes a new specific primer to detect virulence-related genes from $V$. cholerae and $V$. vulnificus. This advanced MPN-PCR method was verified using bioaccumulated pacific oysters (Crassostrea gigas) by $V$. cholerae and $V$. vulnificus.

\section{Introduction}

Various Vibrio spp. such as Vibrio cholerae, Vibrio parahaemolyticus, and Vibrio vulnificus are known as foodborne pathogens and have been reported to cause bacterial enteritis and sepsis (Khan et al., 2020). The illnesses caused by these bacteria commonly occur in the intake of raw or undercooked fishery products and wounds that are created during fish processing (Panicker et al., 2004). Among these species, $V$. vulnificus is one of the most deadly infectious halophilic species known to cause septicemia. In immunocompromised patients, the lethality of $V$. vulnificus septicemia has been reported more than $50 \%$ within 1-2 days after onset of symptoms (Starks et al., 2000). Virulence factors of $V$. vulnificus that are known to evoke disease include hemolysin, protease, and siderophore (iron chelator). In addition, some of the genes such as $v v h$ ( $V$. vulnificus hemolysin), $v i u B$ (vibriobactin utilization), and $v c g C$ (virulencecorrelated gene $\mathrm{C}$ sequence) in this species are involved in the synthesis of these factors (Guling et al., 2005; Han et al., 2011; Jones et al., 2009).

Some of the Vibrio sp. such as V. cholerae serotype 01 and serotype 0139 are known to cause cholera. Although, currently, these serotypes are no longer a fatal waterborne infection in countries where there is safe drinking water and advanced sanitation systems, such as Europe and North America. However, there is still a fatal disease caused by $V$. cholerae in many countries, particularly in at least 47 countries, where 2.9 million cases with 95,000 death occurred by its infections (Ail et al., 2015; WHO, 2017). The virulence factors of $V$. cholerae are highly diverse, and some of these include cholera toxin (CT), toxin coregulated pilus (TCP), zonula occludens toxin (ZOT), accessory cholera toxin (Ace), etc. (Singh et al., 2001; Gao et al., 2019). The genes associated with these virulence factors, such as $\operatorname{ctx} A$ (subunit $A$ of cholera toxin), 
$t c p /$ (toxin coregulated pilus inhibitor), and zot (zonula occludens toxin) are reported to get upregulated during the time of its infections (Singh et al., 2001; Gao et al., 2019).

According to the World Health Organization (WHO), the number of reported cholera cases is less as compared to the actual circumstances, which is due to the limitations of the disease observation system, inaccurate case definitions, and limits of laboratory analysis capabilities (WHO, 2016). Various culturebased methods using selective-differential media, such as thiosulfate-citrate-bile-sucrose (TCBS) agar and

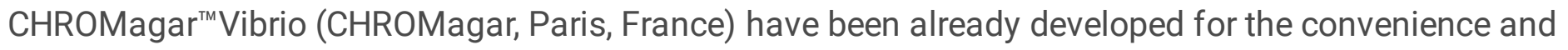
high accuracy detection of pathogenic Vibrio spp. (Rosec et al., 2012; Zavala-Norzagaray et al., 2015; Stuart et al., 2016). However, due to the strong selective properties of these media, the culture-based approaches are challenging to isolate and detect the damaged cells (Alam et al., 2003). Furthermore, these selective-differential media are also not suitable for the isolation of the pathogenic $V$. cholerae and $V$. vulnificus from the environment. In the case of TCBS, the colonies of $V$. cholerae (yellow color) can be distinguished from other Vibrio spp. (olive or green color) based on the appearance of the colored cells which is occurred due to the changes in $\mathrm{pH}$ of the media through sucrose fermentation (Nigro et al., 2011). Similarly, the colonies of other Vibrio species such as Vibrio alginolyticus and $V$. vulnificus also form yellow color colonies after growing in TCBS media (Bunpa et al., 2016; Passalacqua et al., 2016). However, blue color colonies of $V$. cholerae (light blue) and $V$. vulnificus (dark blue) have been reported to occur after growing on CHROMagar ${ }^{\mathrm{TM}}$ Vibrio (Deeb et al., 2018).

In the current trends, the polymerase chain reaction (PCR) based detection of the bacterial culture has become an effective and advanced technology to solve problems that arise in the culture-based methods. Although it has certain advantages such as rapid analysis and high accuracy, some of the PCR methods (real-time PCR) are expensive for the enumeration of bacteria (Levin, 2004; Gyawali et al., 2015). Furthermore, for the enumeration of more than two species of pathogenic Vibrio spp. at the same time, a real-time multiplex PCR using fluorescence oligonucleotide probe is required, which is also costly as compared to simple qPCR (quantitative PCR) with SYBR-Green (Qvarnstrom et al., 2005; Kim et al., 2012). Hence, due to the high experimental cost, the above PCR-based detection and management of pathogenic bacteria might be one of its limitations in developing countries (Chan et al., 2016; Nyaruaba et al, 2019). To solve the above problem, the MPN-PCR method combining with the most probable number (MPN) method has been developed (Barrera et al., 2016). However, the MPN-PCR method is not suitable for the detection and isolation of different pathogenic Vibrio spp. and strains, though this method is suitable only for bacterial enumeration (Andrews et al., 2000; Rivera et al., 2001; Shaw et al., 2014; Bonny et al., 2018). In addition, some strains of $V$. vulnificus are also had problems with isolation because these bacteria have weak viability when storing at low temperatures without preservation treatment (Burnham, et al., 2009). To overcome the limitation of the MPN-PCR method employed for the enumeration of the Vibrio spp. we developed a low-cost and accurate detection method, which is the combination of MPN-PCR and cultural methods. The developed advanced MPN-PCR method in the present study is very helpful for the enumeration and isolation of pathogenic $V$. cholerae and $V$. vulnificus as tested and verified for their detection from the environmental samples. 


\section{Materials And Methods}

\subsection{Bacterial strain and growth media}

For the development and verification of the advanced MPN-PCR method, three reference strains, six environmental isolates, and one DNA from reference strain were used in this study (Table 1). The reference strains such as V. alginolyticus (KCTC 2472), V. cholerae 0139 (MFDS-2003487), and Vibrio vulnificus (KCCM 41662) were purchased from the Korean Culture Center of Microorganism (KCCM; Seoul, Korea), Korean Collection for Type Culture (KCTC; Jeongeup, Korea), and Korean Culture Collection for Foodborne Pathogens (the Ministry of Food and Drug Safety, Cheongju, Korea). The chromosomal DNA of $V$. cholerae 01 was obtained from the Korean Culture Center of Microorganisms (KCCM), and it was stored at $-20^{\circ} \mathrm{C}$ and using for the experiment. In addition, the environmental isolates of Vibrio spp. such as $V$. cholerae (VCGS-1 strain) and V. vulnificus (VVBS-1, VVBS-2, VVGN, VVGS-1, and VVGS-2 strains) have also been used in this study. These strains were obtained from the Laboratory of food hygiene and microbiology (Gangneung-wonju national university, Gangneug, Korea), Laboratory of food hygiene (Gunsan national university, Gunsan, Korea), and isolated from Geoje in 2018. For the enrichment of bacteria, alkaline peptone water (Merck Millipore, Germany, APW, pH 8.6 \pm 0.2 ) and double concentration APW (2× APW) were used. At the same time, TCBS (Difco, Detroit, Ml; pH 8.6 \pm 0.2 ) and Luria-Bertani agar (LBA) without supplementation of $\mathrm{NaCl}(\mathrm{LB}-0)$ were used as a selective-differential growth media. However, for the

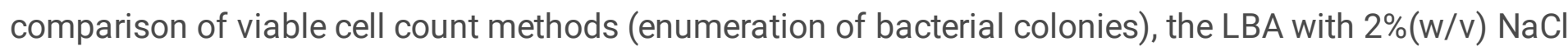
(LB-2, with additional supplementation of $10 \mathrm{~g} / \mathrm{L} \mathrm{NaCl}$ ) has been used. 
Table 1

List of bacterial strains used in this study

\begin{tabular}{|c|c|c|}
\hline Strains & $\begin{array}{l}\text { Virulence- } \\
\text { related } \\
\text { gene }\end{array}$ & Sources \\
\hline $\begin{array}{l}\text { Vibrio alginolyticus KCTC } \\
2472\end{array}$ & - & Korean Collection for Type Cultures \\
\hline $\begin{array}{l}\text { Vibrio cholerae } 01 \mathrm{KCCM} \\
41626 \text { (chromosomal DNA) }\end{array}$ & $\begin{array}{l}\text { ctxA, tcpl, } \\
\text { zot }\end{array}$ & Korean Culture Center of Microorganism \\
\hline $\begin{array}{l}\text { V. cholerae } 0139 \text { MFDS- } \\
2003487\end{array}$ & tcpl, zot & Korean Culture Collection for Foodborne Pathogens \\
\hline V. cholerae 0139 VCGS-1 & tcpl, zot & $\begin{array}{l}\text { Laboratory of food hygiene, Gunsan national university, } \\
\text { Gunsan, Korea }\end{array}$ \\
\hline $\begin{array}{l}\text { Vibrio vulnificus KCCM } \\
41665\end{array}$ & vvh, viuB & Korean Culture Center of Microorganism \\
\hline V. vulnificus VVBS-1 & $v v h, v c g C$ & Isolated from seawater at Geoje, Korea \\
\hline V. vulnificus VVBS-2 & $\begin{array}{l}\text { vvh, viuB, } \\
\operatorname{vcg} C\end{array}$ & Isolated from seawater at Geoje, Korea \\
\hline V. vulnificus VVGN & $\begin{array}{l}\text { vvh, viuB, } \\
\text { vcgC }\end{array}$ & $\begin{array}{l}\text { Laboratory of food hygiene and microbiology, } \\
\text { Gangneung-wonju national university, Gangneung, Korea }\end{array}$ \\
\hline V. vulnificus VVGS-1 & $v v h, v c g C$ & $\begin{array}{l}\text { Laboratory of food hygiene, Gunsan national university, } \\
\text { Gunsan, Korea }\end{array}$ \\
\hline V. vulnificus VVGS-2 & $\begin{array}{l}\text { vvh, viuB, } \\
\operatorname{vcg} C\end{array}$ & $\begin{array}{l}\text { Laboratory of food hygiene, Gunsan national university, } \\
\text { Gunsan, Korea }\end{array}$ \\
\hline \multicolumn{3}{|c|}{$\begin{array}{l}\text { ctxA, Cholera toxin A. } t c p l \text {, Toxin coregulated pilus inhibitor. zot, Zonula occludens toxin. } v v h \text {, Vibrio } \\
\text { vulnificus hemolysin. viuB, Vibriobactin utilization. } v c g C \text {, Virulence-correlated gene C sequence }\end{array}$} \\
\hline
\end{tabular}

Alive oyster (Crassostrea gigas) samples were purchased from an aquaculture farm located in TongYeong, Gyeongnam, Korea. Oyster samples were harvested in February 2019 and transported to the laboratory within $4 \mathrm{~h}$ under keeping less than $10^{\circ} \mathrm{C}$. Oysters were washed briefly with tap water to remove bows from shells. To remove the debris from inside of the oysters, the samples were placed in a tank (high-density polyethylene with a dimension of $50 \times 55 \times 60 \mathrm{~cm}$ ) containing $100 \mathrm{~L}$ of artificial seawater (ASW; salinity $35 \mathrm{psu}$ ) at $15^{\circ} \mathrm{C}$ for $14-16 \mathrm{~h}$ that was also continuously circulated. ASW was prepared by dissolving with $17.5 \mathrm{~g} / \mathrm{L}$ of artificial sea salt (Reef Salt Mix; KENT Marine, Long Beach, CA) and 17.5g/L of sea salt (Hanju Salt., Ulsan, Korea). The recirculation of ASW was carried out using a pump with a flow rate of $480 \mathrm{~L} / \mathrm{h}(8 \mathrm{~L} / \mathrm{min})$ to ensure sufficient dissolved oxygen in the water. The $V$. vulnificus KCCM 41665 and $V$. cholerae 0139 MFDS-2003487 were inoculated in the tank at the cell population of $10^{6} \mathrm{CFU} / \mathrm{mL}$. 
The bioaccumulation of these Vibrio spp. was conducted for $6 \mathrm{~h}$ following the previous report (Martins et al., 2006).

\subsection{Sample collection and preparation}

Seawater and seafood samples were collected from February 2019 to October 2019 at the southeast coastal area and from a local market and consignment market at Tong-Yeong, Gyeongnam, Korea (Fig. 1). The details of sample information were shown in Table 2. The samples were prepared according to the procedure described by the U.S. Food and Drug Administration Bacteriological Analytical Manual (FDABAM): Vibrio (Bonnin-Jusserand et al., 2019). The samples were washed with tap water to remove the muds present on the shell. After removing shells, $50 \mathrm{~g}$ of meat (including liquid) was mixed with $450 \mathrm{~g}$ of $0.1 \mathrm{M}$ phosphate-buffered saline (PBS, $\mathrm{pH} 7.2 \pm 0.2$ ) and blended for $90 \mathrm{sec}$. Seawater samples were directly used without any pretreatment. 
Table 2

Sample information collected from local-market, consignment market and south-east coastal area of Korea

\begin{tabular}{|c|c|c|}
\hline Sampling month & Sample & Number of samples \\
\hline \multirow[t]{2}{*}{ February } & Swimming crab (Portunus trituberculatus) & 15 \\
\hline & Longarm octopus (Octopus minor) & 15 \\
\hline \multirow[t]{2}{*}{ March } & Swimming crab (Portunus trituberculatus) & 15 \\
\hline & Longarm octopus (Octopus minor) & 15 \\
\hline \multirow[t]{3}{*}{ April } & Swimming crab (Portunus trituberculatus) & 15 \\
\hline & Longarm octopus (Octopus minor) & 15 \\
\hline & Seawater & 9 \\
\hline \multirow[t]{3}{*}{ May } & Swimming crab (Portunus trituberculatus) & 15 \\
\hline & Longarm octopus (Octopus minor) & 15 \\
\hline & Seawater & 9 \\
\hline \multirow[t]{3}{*}{ June } & Swimming crab (Portunus trituberculatus) & 15 \\
\hline & Longarm octopus (Octopus minor) & 15 \\
\hline & Seawater & 9 \\
\hline \multirow[t]{3}{*}{ July } & Swimming crab (Portunus trituberculatus) & 15 \\
\hline & Longarm octopus (Octopus minor) & 15 \\
\hline & Seawater & 9 \\
\hline August & Gizzard shad (Konosirus punctatus) & 18 \\
\hline \multirow[t]{2}{*}{ September } & Gizzard shad (Konosirus punctatus) & 18 \\
\hline & Seawater & 9 \\
\hline \multirow[t]{2}{*}{ October } & Gizzard shad (Konosirus punctatus) & 18 \\
\hline & Seawater & 9 \\
\hline Total & - & 288 \\
\hline
\end{tabular}

\subsection{Isolation of Vibrio spp. from samples}

APW enrichment was performed to recover the damaged cells(Humphries et al., 2015) and to enumerate the cell population using an MPN method. The enrichment procedure was performed according to the 3tubes APW enrichment procedure from FDA-BAM: Vibrio (Bonnin-Jusserand et al., 2019). The inoculate procedure, as shown in Fig. 2, and the inoculated culture media were incubated for $18 \mathrm{~h}$ at $35 \pm 2^{\circ} \mathrm{C}$. After 
APW enrichment, positive tubes were recognized based on turbidity. Further, to confirm Vibrio spp. from the positive tubes, the cell culture was streaked on a TCBS agar plate and incubated at $35^{\circ} \mathrm{C}$ for $18 \mathrm{~h}$. The green-colored colony on the 1st TCBS agar plate was sub-cultured on the 2nd TCBS agar plate using streaking. Also, the yellow-colored colony was sub-cultured on the LB-0 agar plate and incubated under the same conditions (Fig. 3).

\subsection{Identification of Vibrio spp. using PCR with specific primer}

Genomic DNA (gDNA) for PCR analysis was extracted using AccuPrep ${ }^{\circledR}$ Genomic DNA Extraction Kit (Bioneer, Daejeon, Korea) according to the instruction given in the manual as provided by the manufacturer. The AccuPower ${ }^{\circledR}$ PCR premix (Bioneer, Daejeon, Korea), PCR primers, and the 100bp Plus DNA ladder (Bioneer, Daejeon, Korea) used in this study were purchased from Bioneer (Daejeon, Korea). The PCR analysis was performed for the identification between Vibrio spp., V. cholerae serotype, and virulence-related genes. PCR conditions and primers used in the present study were shown in Table 3, 4, and the PCR was carried using TaKaRa PCR Thermal Cycler Dice ${ }^{\circledR}$ Gradient (Takara-bio, Kusatsu, Japan). The primers suggested by this study were newly designed based on the analysis of Primer-BLAST ${ }^{\circledR}$ (National Center for Biotechnology Information, Bethesda, MD). 
Table 3

Primers and conditions used in the PCR for the confirmation of Vibrio vulnificus, Vibrio cholerae, and pathogenic serotype of Vibrio cholerae

\begin{tabular}{|c|c|c|c|c|c|}
\hline $\begin{array}{l}\text { PCR } \\
\text { Target }\end{array}$ & Oligonucleotide sequence & \multicolumn{2}{|c|}{ PCR conditions } & $\begin{array}{l}\text { Product } \\
\text { Size (bp) }\end{array}$ & References \\
\hline \multirow[t]{6}{*}{$\begin{array}{l}\text { V. } \\
\text { vulnificus }\end{array}$} & \multirow{3}{*}{$\begin{array}{l}\text { 5'- } \\
\text { CAGCCGGACGTCGTCCATTTTG - } \\
3^{\prime}\end{array}$} & $\begin{array}{l}94^{\circ} \mathrm{C} 5 \\
\min \end{array}$ & $\begin{array}{l}1 \\
\text { cycles }\end{array}$ & \multirow[t]{6}{*}{484} & \multirow[t]{6}{*}{$\begin{array}{l}\text { (Jang et al., } \\
2018)\end{array}$} \\
\hline & & $\begin{array}{l}94^{\circ} \mathrm{C} \\
30 \mathrm{sec}\end{array}$ & $\begin{array}{l}25 \\
\text { cycles }\end{array}$ & & \\
\hline & & $60^{\circ} \mathrm{C}$ & & & \\
\hline & \multirow{3}{*}{$\begin{array}{l}\text { 5'- ATGAGTAAGCGTCCGACGCGT } \\
-3^{\prime}\end{array}$} & & & & \\
\hline & & $\begin{array}{l}72^{\circ} \mathrm{C} \\
30 \mathrm{sec}\end{array}$ & & & \\
\hline & & $\begin{array}{l}72^{\circ} \mathrm{C} 4 \\
\min \end{array}$ & $\begin{array}{l}1 \\
\text { cycles }\end{array}$ & & \\
\hline \multirow{6}{*}{$\begin{array}{l}\text { V. } \\
\text { cholerae } \\
(\text { ompW) }\end{array}$} & \multirow{3}{*}{$\begin{array}{l}\text { 5'- } \\
\text { CACCAAGAAGGTGACTTTATTGTG } \\
-3^{\prime}\end{array}$} & $\begin{array}{l}94^{\circ} \mathrm{C} 5 \\
\min \end{array}$ & $\begin{array}{l}1 \\
\text { cycles }\end{array}$ & \multirow[t]{6}{*}{304} & \multirow[t]{6}{*}{$\begin{array}{l}\text { (Bisweswar et } \\
\text { al., 2000) }\end{array}$} \\
\hline & & $\begin{array}{l}94^{\circ} \mathrm{C} \\
30 \mathrm{sec}\end{array}$ & $\begin{array}{l}30 \\
\text { cycles }\end{array}$ & & \\
\hline & & $\begin{array}{l}64^{\circ} \mathrm{C} \\
30 \mathrm{sec}\end{array}$ & & & \\
\hline & \multirow[t]{3}{*}{$\begin{array}{l}\text { 5'- GGTTTGTCGAATTAGCTTCACC } \\
-3^{\prime}\end{array}$} & & & & \\
\hline & & $\begin{array}{l}72^{\circ} \mathrm{C} \\
30 \mathrm{sec}\end{array}$ & & & \\
\hline & & $\begin{array}{l}72^{\circ} \mathrm{C} 4 \\
\min \end{array}$ & $\begin{array}{l}1 \\
\text { cycles }\end{array}$ & & \\
\hline \multirow[t]{5}{*}{$01 r f b$} & \multirow[t]{3}{*}{ 5'- GTTTCACTGAACAGATGGG - 3' } & $\begin{array}{l}94^{\circ} \mathrm{C} 5 \\
\min \end{array}$ & $\begin{array}{l}1 \\
\text { cycles }\end{array}$ & \multirow[t]{5}{*}{192} & \multirow[t]{5}{*}{$\begin{array}{l}\text { (Shimada et al., } \\
\text { 2006) }\end{array}$} \\
\hline & & $\begin{array}{l}94^{\circ} \mathrm{C} \\
30 \mathrm{sec}\end{array}$ & $\begin{array}{l}35 \\
\text { cycles }\end{array}$ & & \\
\hline & & $\begin{array}{l}60^{\circ} \mathrm{C} \\
30 \mathrm{sec}\end{array}$ & & & \\
\hline & \multirow{2}{*}{ 5'- GGTCATCTGTAAGTACAAC - 3' } & $\begin{array}{l}72^{\circ} \mathrm{C} \\
30 \mathrm{sec}\end{array}$ & & & \\
\hline & & $\begin{array}{l}72^{\circ} \mathrm{C} 4 \\
\min \end{array}$ & $\begin{array}{l}1 \\
\text { cycles }\end{array}$ & & \\
\hline
\end{tabular}




\begin{tabular}{|c|c|c|c|c|c|}
\hline $\begin{array}{l}\text { PCR } \\
\text { Target }\end{array}$ & Oligonucleotide sequence & \multicolumn{2}{|c|}{ PCR conditions } & Product & References \\
\hline \multirow[t]{5}{*}{$0139 r f b$} & \multirow[t]{3}{*}{$\begin{array}{l}\text { 5'- AGCCTCTTTATTACGGGTGG - } \\
3^{\prime}\end{array}$} & $\begin{array}{l}94^{\circ} \mathrm{C} 5 \\
\min \end{array}$ & $\begin{array}{l}1 \\
\text { cycles }\end{array}$ & \multirow[t]{5}{*}{449} & \\
\hline & & $\begin{array}{l}94^{\circ} \mathrm{C} \\
30 \mathrm{sec}\end{array}$ & $\begin{array}{l}35 \\
\text { cycles }\end{array}$ & & \\
\hline & & $60^{\circ} \mathrm{C}$ & & & \\
\hline & \multirow[t]{2}{*}{$\begin{array}{l}\text { 5'- GTCAAACCCGATCGTAAAGG - } \\
\text { 3' }\end{array}$} & $\begin{array}{l}30 \mathrm{sec} \\
72^{\circ} \mathrm{C} \\
30 \mathrm{sec}\end{array}$ & & & \\
\hline & & $\begin{array}{l}72^{\circ} \mathrm{C} 4 \\
\min \end{array}$ & $\begin{array}{l}1 \\
\text { cycles }\end{array}$ & & \\
\hline
\end{tabular}


Table 4

Primers and conditions used in the PCR for detecting virulence-related genes of Vibrio spp.

\begin{tabular}{|c|c|c|c|c|c|c|}
\hline Species & $\begin{array}{l}\text { PCR } \\
\text { Target }\end{array}$ & Oligonucleotide sequence & PCR cor & itions & $\begin{array}{l}\text { Product } \\
\text { Size } \\
\text { (bp) }\end{array}$ & References \\
\hline \multirow[t]{17}{*}{$\begin{array}{l}\text { V. } \\
\text { cholerae }\end{array}$} & \multirow[t]{4}{*}{$\operatorname{ctxA}$} & \multirow{3}{*}{$\begin{array}{l}\text { 5'- } \\
\text { CTCAGACGGGATTTGTTAGGCACG } \\
-3^{\prime}\end{array}$} & $\begin{array}{l}94^{\circ} \mathrm{C} 5 \\
\min \end{array}$ & $\begin{array}{l}1 \\
\text { cycles }\end{array}$ & \multirow[t]{4}{*}{302} & \multirow[t]{4}{*}{$\begin{array}{l}\text { (Jiang et } \\
\text { al., 2018) }\end{array}$} \\
\hline & & & $\begin{array}{l}94^{\circ} \mathrm{C} \\
30 \mathrm{sec}\end{array}$ & $\begin{array}{l}30 \\
\text { cycles }\end{array}$ & & \\
\hline & & & $\begin{array}{l}55^{\circ} \mathrm{C} \\
30 \mathrm{sec}\end{array}$ & & & \\
\hline & & $\begin{array}{l}5^{\prime}- \\
\text { TCTATCTCTGTAGCCCCTATTACG } \\
-3^{\prime}\end{array}$ & $\begin{array}{l}72^{\circ} \mathrm{C} \\
30 \mathrm{sec}\end{array}$ & & & \\
\hline & \multirow[t]{8}{*}{ tcpl } & \multirow[t]{3}{*}{$\begin{array}{l}\text { 5'- TAGCCTTAGTTCTCAGCAGGCA } \\
-3^{\prime}\end{array}$} & $\begin{array}{l}94^{\circ} \mathrm{C} 5 \\
\min \end{array}$ & $\begin{array}{l}1 \\
\text { cycles }\end{array}$ & \multirow[t]{4}{*}{862} & \multirow[t]{4}{*}{$\begin{array}{l}\text { (Singh et } \\
\text { al., 2001) }\end{array}$} \\
\hline & & & $\begin{array}{l}94^{\circ} \mathrm{C} \\
30 \mathrm{sec}\end{array}$ & $\begin{array}{l}30 \\
\text { cycles }\end{array}$ & & \\
\hline & & & $\begin{array}{l}60^{\circ} \mathrm{C} \\
30 \mathrm{sec}\end{array}$ & & & \\
\hline & & $\begin{array}{l}5^{\prime}-\text { GGCAATAGTGTCGAGCTCGTTA } \\
-3^{\prime}\end{array}$ & $\begin{array}{l}72^{\circ} \mathrm{C} \\
55 \mathrm{sec}\end{array}$ & & & \\
\hline & & \multirow[t]{2}{*}{$\begin{array}{l}\text { 5'- GCCTTAGTTCTCAGCAGGCA - } \\
3^{\prime}\end{array}$} & $\begin{array}{l}94^{\circ} \mathrm{C} 5 \\
\min \end{array}$ & $\begin{array}{l}1 \\
\text { cycles }\end{array}$ & \multirow[t]{4}{*}{439} & \multirow[t]{4}{*}{ This study } \\
\hline & & & $\begin{array}{l}94^{\circ} \mathrm{C} \\
30 \mathrm{sec}\end{array}$ & $\begin{array}{l}30 \\
\text { cycles }\end{array}$ & & \\
\hline & & \multirow{2}{*}{$\begin{array}{l}\text { 5'- AACATCCCACTGCCGTTAGG - } \\
3^{\prime}\end{array}$} & $\begin{array}{l}56.2^{\circ} \mathrm{C} \\
30 \mathrm{sec}\end{array}$ & & & \\
\hline & & & $\begin{array}{l}72^{\circ} \mathrm{C} \\
55 \mathrm{sec} \\
72^{\circ} \mathrm{C} 4 \\
\min \end{array}$ & $\begin{array}{l}1 \\
\text { cycles }\end{array}$ & & \\
\hline & \multirow[t]{5}{*}{$z o t$} & \multirow{3}{*}{$\begin{array}{l}5^{\prime}- \\
\text { CACTGTTGGTGATGAGCGTTATCG } \\
-3^{\prime}\end{array}$} & $\begin{array}{l}94^{\circ} \mathrm{C} 5 \\
\min \end{array}$ & $\begin{array}{l}1 \\
\text { cycles }\end{array}$ & \multirow[t]{4}{*}{243} & \multirow[t]{4}{*}{$\begin{array}{l}\text { (Gao et al., } \\
\text { 2019) }\end{array}$} \\
\hline & & & $\begin{array}{l}94^{\circ} \mathrm{C} \\
30 \mathrm{sec}\end{array}$ & $\begin{array}{l}30 \\
\text { cycles }\end{array}$ & & \\
\hline & & & $\begin{array}{l}55^{\circ} \mathrm{C} \\
30 \mathrm{sec}\end{array}$ & & & \\
\hline & & $\begin{array}{l}5^{\prime}- \\
\text { TTTCACTTCTACCCACAGCGCTTG } \\
-3^{\prime}\end{array}$ & $\begin{array}{l}72^{\circ} \mathrm{C} \\
55 \mathrm{sec}\end{array}$ & & & \\
\hline & & $\begin{array}{l}\text { 5'- TAACGATGGCGCGTTTTTGG - } \\
3^{\prime}\end{array}$ & $\begin{array}{l}94^{\circ} \mathrm{C} 5 \\
\min \end{array}$ & $\begin{array}{l}1 \\
\text { cycles }\end{array}$ & 257 & This study \\
\hline
\end{tabular}




\begin{tabular}{|c|c|c|c|c|c|c|}
\hline \multirow[t]{2}{*}{ Species } & \multirow{2}{*}{$\begin{array}{l}\text { PCR } \\
\text { Target }\end{array}$} & \multirow{2}{*}{$\begin{array}{l}\text { Oligonucleotide sequence } \\
\text { 5'- TATCTCCGCCGCCTCTCTTA - } \\
\text { 3' }\end{array}$} & \multicolumn{2}{|c|}{ PCR conditions } & \multirow{2}{*}{$\begin{array}{l}\text { Product } \\
\text { Size } \\
\text { (bp) }\end{array}$} & \multirow[t]{2}{*}{ References } \\
\hline & & & $\begin{array}{l}94^{\circ} \mathrm{C} \\
30 \mathrm{sec}\end{array}$ & $\begin{array}{l}35 \\
\text { cycles }\end{array}$ & & \\
\hline & & & $\begin{array}{l}56.2^{\circ} \mathrm{C} \\
30 \mathrm{sec}\end{array}$ & & & \\
\hline & & & $\begin{array}{l}72^{\circ} \mathrm{C} \\
30 \mathrm{sec}\end{array}$ & & & \\
\hline & & & $\begin{array}{l}72^{\circ} \mathrm{C} 4 \\
\min \end{array}$ & $\begin{array}{l}1 \\
\text { cycles }\end{array}$ & & \\
\hline
\end{tabular}


Table 4

Primers and conditions used in the PCR for detecting virulence-related genes of Vibrio spp. (continue)

\begin{tabular}{|c|c|c|c|c|c|c|}
\hline Species & $\begin{array}{l}\text { PCR } \\
\text { Target }\end{array}$ & Oligonucleotide sequence & PCR CO & ditions & $\begin{array}{l}\text { Product } \\
\text { Size } \\
\text { (bp) }\end{array}$ & Reference \\
\hline \multirow[t]{16}{*}{$\begin{array}{l}V . \\
\text { vulnificus }\end{array}$} & \multirow[t]{5}{*}{$v v h$} & \multirow{3}{*}{$\begin{array}{l}5^{\prime}- \\
\text { TTCCAACTTCAAACCGAACTATGAC } \\
-3^{\prime}\end{array}$} & $\begin{array}{l}94^{\circ} \mathrm{C} \\
5 \mathrm{~min}\end{array}$ & $\begin{array}{l}1 \\
\text { cycles }\end{array}$ & \multirow[t]{5}{*}{205} & \multirow{5}{*}{$\begin{array}{l}\text { (Cañigral } \\
\text { et al., } \\
2010 \text { ) }\end{array}$} \\
\hline & & & $\begin{array}{l}94^{\circ} \mathrm{C} \\
30 \\
\text { sec }\end{array}$ & $\begin{array}{l}35 \\
\text { cycles }\end{array}$ & & \\
\hline & & & $\begin{array}{l}65^{\circ} \mathrm{C} \\
30\end{array}$ & & & \\
\hline & & \multirow[t]{2}{*}{$\begin{array}{l}\text { 5'- } \\
\text { ATTCCAGTCGATGCGAATACGTTG } \\
-3^{\prime}\end{array}$} & $\begin{array}{l}\text { sec } \\
72^{\circ} \mathrm{C} \\
30 \\
\text { sec }\end{array}$ & & & \\
\hline & & & $\begin{array}{l}72^{\circ} \mathrm{C} \\
4 \mathrm{~min}\end{array}$ & $\begin{array}{l}1 \\
\text { cycles }\end{array}$ & & \\
\hline & \multirow[t]{6}{*}{$\operatorname{viu} B$} & \multirow{3}{*}{$\begin{array}{l}\text { 5'- } \\
\text { GGTTGGGCACTAAAGGCAGATATA } \\
-3^{\prime}\end{array}$} & $\begin{array}{l}94^{\circ} \mathrm{C} \\
5 \mathrm{~min}\end{array}$ & $\begin{array}{l}1 \\
\text { cycles }\end{array}$ & \multirow[t]{6}{*}{504} & \multirow{6}{*}{$\begin{array}{l}\text { (Panicker } \\
\text { et al., } \\
2004 \text { ) }\end{array}$} \\
\hline & & & $\begin{array}{l}94^{\circ} \mathrm{C} \\
30 \\
\text { sec }\end{array}$ & $\begin{array}{l}30 \\
\text { cycles }\end{array}$ & & \\
\hline & & & $\begin{array}{l}65^{\circ} \mathrm{C} \\
30\end{array}$ & & & \\
\hline & & \multirow{3}{*}{$\begin{array}{l}\text { 5'- CGGCAGTGGACTAATACGCAGC } \\
-3^{\prime}\end{array}$} & sec & & & \\
\hline & & & $\begin{array}{l}72^{\circ} \mathrm{C} \\
35 \\
\text { sec }\end{array}$ & & & \\
\hline & & & $\begin{array}{l}72^{\circ} \mathrm{C} \\
4 \mathrm{~min}\end{array}$ & $\begin{array}{l}1 \\
\text { cycles }\end{array}$ & & \\
\hline & \multirow[t]{5}{*}{$v c g C$} & \multirow[t]{2}{*}{ 5'- AGCTGCCGATAGCGATCT - 3' } & $\begin{array}{l}94^{\circ} \mathrm{C} \\
5 \mathrm{~min}\end{array}$ & $\begin{array}{l}1 \\
\text { cycles }\end{array}$ & \multirow[t]{5}{*}{278} & \multirow[t]{5}{*}{$\begin{array}{l}\text { (Yokochi } \\
\text { et al., } \\
2013 \text { ) }\end{array}$} \\
\hline & & & $\begin{array}{l}94^{\circ} \mathrm{C} \\
30 \\
\text { sec }\end{array}$ & $\begin{array}{l}35 \\
\text { cycles }\end{array}$ & & \\
\hline & & \multirow[t]{3}{*}{ 5'- CGCTTAGGATGATCGGTG - 3' } & $\begin{array}{l}56^{\circ} \mathrm{C} \\
30 \\
\text { sec }\end{array}$ & & & \\
\hline & & & $\begin{array}{l}72^{\circ} \mathrm{C} \\
30 \\
\text { sec }\end{array}$ & & & \\
\hline & & & $\begin{array}{l}72^{\circ} \mathrm{C} \\
4 \mathrm{~min}\end{array}$ & $\begin{array}{l}1 \\
\text { cycles }\end{array}$ & & \\
\hline
\end{tabular}




\subsection{Statistical analysis}

The simultaneous cell enumeration of $V$. cholerae and $V$. vulnificus using artificially bioaccumulated oyster was carried out in triplicate. The MPN table listed in FDA-BAM Appendix 2 (Bonnin-Jusserand et al., 2019) was used for the cell enumeration. Results are expressed as mean \pm standard deviation. Statistics were processed using Duncan's multiple range test $(P<0.05)$ with SPSS (v.23.0, SPSS Ine., Chicago, IL) after performing analysis of variance (ANOVA) for significance-verification (Duncan, 1955).

\section{Results}

\subsection{Isolation and identification of V. cholerae using non- $\mathrm{NaCl}$ growth media and advanced MPN-PCR method}

The LB-0 agar was formulated as an effective selection media for the sub-culturing of $V$. cholerae that were isolated by growing on TCBS agar plate. For the selection of $V$. cholerae using LB- 0 agar selection media, a total of nine strains of Vibrio spp. were inoculated to the LB-0 agar plate that was pre-cultured on the TCBS agar plate, and results are shown in Table 5 . The results showed that only $V$. cholerae strains were found to grow on the LB-0 agar plate until $24 \mathrm{~h}$. This result indicates that LB- 0 agar is an effective selection media for the isolation of $V$. cholerae that were initially grown on a TCBS agar plate.

Table 5

The cultural response of various Vibrio spp. inoculate from TCBS agar

\begin{tabular}{|lll|}
\hline Strains & \multicolumn{2}{l|}{ Recovery by incubation time at $\mathbf{3 5}^{\circ} \mathrm{C}$} \\
\cline { 2 - 4 } & $\mathbf{1 2}$ hours & $\mathbf{2 4}$ hours \\
\hline Vibrio alginolyticus KCTC 2472 & None & None \\
\hline V. cholerae 0139 MFDS-2003487 & Good & Good \\
\hline V. cholerae 0139 VCGS-1 & Good & Good \\
\hline Vibrio vulnificus KCCM 41665 & None & None \\
\hline V. vulnificus VVBS-1 & None & None \\
\hline V. vulnificus VVBS-2 & None & None \\
\hline V. vulnificus VVGN & None & None \\
\hline V. vulnificus VVGS-1 & None & None \\
\hline V. vulnificus VVGS-2 & None & None \\
\hline
\end{tabular}

\subsection{Improvement of the accuracy and specificity of the advanced MPN-PCR method}


The amplification of virulence-related genes of $V$. cholerae is an effective way for its identification. Previous research showed that the amplification of virulence-related genes using PCR primer for the identification of $V$. cholerae as suggested by Gao et al. (2019) and Singh et al.(2004). These PCR primers were designed to detect the $t c p /$ and zot virulence genes, but it gives a weak amplification by PCR along with amplification of non-specific products (Fig. 4). To solve the above problem, in the present study, new primers for $t c p /$ and zot genes have been designed using Primer-BLAST ${ }^{\circ}$. As shown in Fig. 4, a good PCR product has been amplified using newly designed primers for the detection of target genes as compared to the previous studies. The $t c p /$ gene-specific primer, as suggested by Singh et al. (2001) were reported to amplify 862 bp PCR product, however, a non-specific PCR product of about 600 bp was also amplified. However, in the present study, the PCR amplification using a newly designed primer was found to exhibit a 439 bp PCR product. In the case of zot gene detection, the previous PCR process, as suggested by Gao et al. (2019) showed 243 bp PCR product of target along with few non-specific PCR products. However, the amplification of zot gene using the newly designed primers resulted in $257 \mathrm{bp}$ amplification.

3.3 Verification of the advanced MPN-PCR method on enumerating oyster bioaccumulated V. cholerae and V. vulnificus cells

The bioaccumulated oysters were used to verify the accuracy and specificity of the modified MPN-PCR method on the enumeration of Vibrio spp.. The obtained results in the present study have also been compared with the results of other Vibrio spp. enumeration methods using different media. As shown in Table 6, no significant difference was observed in the number of Vibrio spp. cell count according to the enumeration method using different media (LB-0 medium, LB-2 medium, and APW medium for MPN-PCR), but not for $V$. vulnificus on LB- 0 agar as described above. The viable cell count of $V$. vulnificus in the oyster was found to be $6.64 \pm 0.13 \log$ CFU/g on the LB-2 agar plate and $8.55 \pm 0.47 \log$ MPN/100g as determined using the MPN-PCR method. In the case of $V$. cholerae, the viable cell count was found to be $6.56 \pm 0.13 \mathrm{log}$ CFU/g on LB-0 agar and $6.64 \pm 0.22 \mathrm{log}$ CFU/g on LB-2 agar, and $8.99 \pm 0.38 \mathrm{log}$ MPN/100g as determined using the MPN-PCR method. These results strongly indicate that the modified MPN-PCR method in the present study can be successfully applied to enumerate Vibrio spp. cells in the shellfish samples. 
Comparison of various methods for viable cell quantification

\begin{tabular}{|c|c|c|c|}
\hline \multirow[t]{2}{*}{ Species } & \multicolumn{3}{|c|}{ Method for viable cell quantification } \\
\hline & $\begin{array}{l}\text { Spread-plate method with LB-0 } \\
\text { agar }\end{array}$ & $\begin{array}{l}\text { Spread-plate method with LB-2 } \\
\text { agar }\end{array}$ & $\begin{array}{l}\text { MPN-PCR } \\
\text { method }\end{array}$ \\
\hline \multirow{2}{*}{$\begin{array}{l}\text { V. } \\
\text { cholerae }\end{array}$} & $6.56 \pm 0.13^{a}$ & $6.64 \pm 0.22^{\mathrm{a}}$ & $8.99 \pm 0.38^{a}$ \\
\hline & $(\log \mathrm{CFU} / \mathrm{g})$ & $(\log \mathrm{CFU} / \mathrm{g})$ & $(\log$ MPN/100g) \\
\hline \multirow[t]{2}{*}{$\begin{array}{l}\text { V. } \\
\text { vulnificus }\end{array}$} & - & $6.64 \pm 0.13^{b}$ & $8.55 \pm 0.47^{b}$ \\
\hline & & $(\log \mathrm{CFU} / \mathrm{g})$ & $(\log$ MPN/100g) \\
\hline
\end{tabular}

\subsection{Simultaneous isolation and enumeration of V. cholerae and V. vulnificus from environmental samples}

The development of the advanced MPN-PCR method in the present study has also been tested for the isolation and enumeration of the Vibrio spp. (both $V$. cholerae and $V$. vulnificus) using environmental samples (Fig. 5). Total 288 seawater and seafood samples were collected from the local market, consignment market, and the coastal area of Korea for over 9 months. As suggested in this study, this method is capable of simultaneously isolating and enumerating $V$. cholerae and $V$. vulnificus cells (Table 7). With the help of the modified MPN-PCR method, the $V$. vulnificus has been detected in the ranges of $<30-36 \mathrm{MPN} / 100 \mathrm{~g}$ (or $100 \mathrm{~mL}$ ) from environmental samples. In addition, two strains of virulent V. vulnificus were isolated from Gizzard shad (Konosirus punctatus) samples which were sampled from different places. And these two environmental isolates have the same virulence-related gene, $v v h$. Whereas $V$. cholerae was detected to $<30 \mathrm{MPN} / 100 \mathrm{~g}$, which is considered as no detection (since the limit of detection is $30 \mathrm{MPN} / 100 \mathrm{~g}$ or $100 \mathrm{~mL}$ ).

Table 7

Result of simultaneous cell quantification and virulence-related gene detection

\begin{tabular}{|llllll|}
\hline Species & $\begin{array}{l}\text { Sampling } \\
\text { month }\end{array}$ & $\begin{array}{l}\text { Collected } \\
\text { location }\end{array}$ & Sample & $\begin{array}{l}\text { Cell count } \\
\text { (MPN/100g) }\end{array}$ & $\begin{array}{l}\text { Detected } \\
\text { Virulence } \\
\text { related gene }\end{array}$ \\
\hline $\begin{array}{l}\text { Vibrio } \\
\text { vulnificus }\end{array}$ & August & $\begin{array}{l}\text { Consignment } \\
\text { market B }\end{array}$ & $\begin{array}{l}\text { Gizzard shad } \\
\text { (Konosirus punctatus) }\end{array}$ & 36 & $v v h$ \\
\hline $\begin{array}{l}\text { Vibrio } \\
\text { vulnificus }\end{array}$ & August & $\begin{array}{l}\text { Consignment } \\
\text { market D }\end{array}$ & $\begin{array}{l}\text { Gizzard shad } \\
\text { (Konosirus punctatus) }\end{array}$ & 36 & $v v h$ \\
\hline * Table only shown results up to LOD (limit of detection, 30 MPN/100g, or $100 \mathrm{~mL}$ ). & \\
\hline
\end{tabular}




\section{Discussion}

It has been reported that a few strains of $V$. vulnificus form a yellow colony after growing on TCBS agar plate, which is similar to the yellow-colored colony of $V$. cholerae (Passalacqua et al., 2016). Hence, the appearance of the yellow color colonies of both species on the TCBS agar plate makes a false identification and enumeration of Vibrio spp.. Thus, due to this problem, the application of the MPN-PCR method will require unnecessary additional time for confirming the $V$. cholerae and $V$. vulnificus, which also makes it difficult to isolates these Vibrio spp.. Similarly, the same problem has also occurred for the identification and isolation of another marine bacterium i.e. $V$. alginolyticus, since this bacterium also forms a yellow colony on TCBS agar plate (Bunpa et al., 2016). Thus, in the MPN-PCR method, unnecessary PCR requirements lead to an increase in the experimental cost and time for the simultaneous enumeration of $V$. cholerae and $V$. vulnificus.

In this study, the application of LB-0 agar supplementation becomes an advantage for the selective culturing and distinguishing $V$. cholerae from the $V$. vulnificus. The reason behind this is due to the different $\mathrm{Na}^{+}$concentrations requirements of different Vibrio spp.. The minimal requirement of $\mathrm{Na}^{+}$ concentrations for $V$. alginolyticus is $200 \mathrm{mM}, V$. cholerae is $5 \mathrm{mM}$, and $V$. vulnificus is $140 \mathrm{mM}$ (Farmer lii et al., 2015). Hence, formulating a selective culture media such as LB-0 agar make it possible to easy identification $V$. cholerae and $V$. vulnificus. This approach with such an advantage can reduce the unnecessary PCR based-identification and is also helpful for simultaneous viable cell enumeration of $V$. cholerae and $V$. vulnificus with low cost. In addition, some strains of $V$. vulnificus are possible to losing activity easily before preservation because some strains have weak viability when storing at low temperatures (Burnham et al., 2009). However, the culture process with LB-0 and TCBS agar also meaning subculture to prevent losing activity of isolates before preservation treatment.

Reports showed that there is a high chance of microbial contamination of bivalve molluscs during its cultivation as compared to the natural environment such as seawater (Campos et al., 2013; Ronald et al., 2008). Due to the highly prone to get contamination, there are many reports showed the food poisoning associated with consuming shellfish that are contaminated with microbial pathogens (Ronald et al., 2008; Anacleto et al., 2014). Depuration is an approach to control the microbial contamination of shellfish using ultra-violet (UV) light treated seawater, and also the Food and Agriculture Organization of the United Nations (UN FAO) recommended that for the same purpose (Lee et al., 2008). Furthermore, to check the efficiency of the depuration, several studies showed the artificial bioaccumulation of the shellfish with the microbial pathogen followed by its enumeration of the cells during the process of depuration (Croci et al., 2002; Marino et al., 2005; Schneider et al., 2009). Martins et al. (2006) and Kwon et al. (2011) reported a clam Thylacodes decussatus and a mussel Mytilus edulis bioaccumulated by Escherichia coli. In this study, we selected pacific oysters for the bioaccumulation of $V$. cholerae and $V$. vulnificus, respectively (detail procedure described in Materials and Methods).

\section{Conclusion}


In the present study, the advanced MPN-PCR method was developed, which adding a culture process using a non- $\mathrm{NaCl}$ medium for simultaneous isolation and enumeration of $V$. cholerae and $V$. vulnificus. The non$\mathrm{NaCl}$ medium was effectively distinguished $V$. cholerae and $V$. vulnificus which are unable to identify using TCBS agar. This simple selective culture process makes it possible to reduce the experimental cost required in the confirmation of $V$. cholerae and $V$. vulnificus using additional PCR analysis. Furthermore, the effectiveness of this advanced MPN-PCR method has also been verified by comparing it with other Vibrio spp. cell enumeration methods. To apply this method in the enumeration of $V$. cholerae and $V$. vulnificus from the environmental samples, these bacteria were bioaccumulated using pacific oyster. Furthermore, this MPN-PCR method has also been applied for bacterial analysis from the environmental samples. From the environmental samples, two virulent $V$. vulnificus have been isolated, which have the characteristic virulence-related gene as evidenced by the PCR amplification. Hence, the present study provides a low-cost MPN-PCR method for the simultaneous isolation and enumeration of $V$. cholerae and $V$. vulnificus that may be helpful for those countries that have low research budgets. This low-cost MPNPCR method will also contribute to the control of microbial risks by intaking seafood that is contaminated with $V$. cholerae and $V$. vulnificus.

\section{Declarations}

\section{Ethics approval and consent to participate}

This article does not contain any studies with human participants or animals performed by any of the authors.

\section{Consent for publication}

The authors give their consent to publish this original article.

\section{Availability of data and material}

Please contact author for data requests.

\section{Competing interests}

Jae-Hwa Lee, Seul-Ki Park, Fazlurrahman Khan, Du-Min Jo, Do-ha Lee, Min-Gyun Kang, and Young-Mog Kim declare that they have no conflict of interest.

\section{Funding}

This research was also a part of the project titled 'Development of on-site diagnosis system for microbiological hazards in the fishery environment, funded by the Ministry of Oceans and Fisheries, Korea. This research was also supported by a National Research Foundation of Korea (NRF) grant funded by the Ministry of Education (2021R1A6A1A03039211). 


\section{Author contribution}

$\mathrm{JHL}$ and YMK designed and lead the writing and analysis of data. JHL, MGK, DHL, and DMJ were performed in the sampling, experiment, and analyzed data. JHL, SKP, FK, and YMK were involved in the data analysis, writing, and editing of the manuscript.

\section{Acknowledgements}

The author acknowledges Dokyun Oh for her technical help during the experiment.

\section{Authors' information}

Not applicable.

\section{References}

Alam MJ, Miyoshi SI, Shinoda S (2003) Studies on pathogenic Vibrio parahaemolyticus during a warm weather season in the Seto Inland Sea, Japan. Environ Microbiol 5:706-710. https://doi.org/10.1046/j.1462-2920.2003.00458.x.

Ali M, Nelson AR, Lopez AL, Sack DA (2015) Updated global burden of cholera in endemic countries. PLoS Negl Trop Dis 9:1-13. https://doi.org/10.1371/journal.pntd.0003832

Anacleto P, Barrento S, Nunes ML, Rosa R, Marques A (2014) Portuguese consumers' attitudes and perceptions of bivalve molluscs. Food Control 41:168-177.

https://doi.org/10.1016/j.foodcont.2014.01.017

Andrews LS, Park DL, Chen YP (2000) Low temperature pasteurization to reduce the risk of vibrio infections from raw shell-stock oysters. Food Addit Contam 17:787-791. https://doi.org/10.1080/026520300415336.

Barrera-Escorcia G, Wong-Chang I, Fernández-Rendón CL, Botello AV, Gómez-Gil B, Lizárraga-Partida ML. (2016) Quantification of Vibrio species in oysters from the Gulf of Mexico with two procedures based on MPN and PCR. Environ Monit Assess 188:602. https://doi.org/10.1007/s10661-016-5620-9

Bisweswar Nandi, Ranjan K. Nandy, Sarmishtha Mukhopadhyay, G Balakrish Nair Toshio Shimada ACG (2000) Rapid method for species-specific identification of Vibrio cholerae using primers targeted to the gene of outer membrane protein OmpW. J Clin Microbiol 38: 4145-4151.

Bonnin-Jusserand M, Copin S, Le Bris C, Brauge T, Gay M, Brisabois A, Grard T, Midelet-Bourdin G (2019) Vibrio species involved in seafood-borne outbreaks (Vibrio cholerae, V. parahaemolyticus and $V$. vulnificus): review of microbiological versus recent molecular detection methods in seafood products. Crit Rev Food Sci Nutr 59:597-610. https://doi.org/10.1080/10408398.2017.1384715. 
Bonny SQ, Hossain MAM, Lin TK, Ali ME (2018) Multiplex MPN-PCR for the enumeration of three major Vibrios in raw fishes in Malaysia. Food Control 90:459-465.

https://doi.org/10.1016/j.foodcont.2018.02.034.

Bunpa S, Sermwittayawong N, Vuddhakul V (2016) Extracellular enzymes produced by Vibrio alginolyticus isolated from environments and diseased aquatic animals. Procedia Chemistry, 18:12-17. https://doi.org/10.1016/j.proche.2016.01.002.

Burnham VE, Janes ME, Jakus LA, Supan J, DePaola A, Bell J (2009) Growth and survival differences of Vibrio vulnificus and Vibrio parahaemolyticus strains during cold storage. J Food Sci 74:M314-M318. https://doi.org/10.1111/j.1750-3841.2009.01227.x.

Campos CJ, Kershaw SR, Lee RJ. (2013) Environmental influences on faecal indicator organisms in coastal waters and their accumulation in bivalve shellfish. Estuaries and coasts, 36:834-853. https://doi.org/10.1007/s12237-013-9599-y.

Chan K, Wong PY, Yu P, Hardick J, Wong KY, Wilson SA, Wu T, Hui Z, Gaydos C, Wong SS (2016) A rapid and low-cost PCR thermal cycler for infectious disease diagnostics. PLoS One 11:1-17. https://doi.org/10.1371/journal.pone.0149150.

Cañigral I, Moreno Y, Alonso JL, González A, Ferrús MA (2010) Detection of Vibrio vulnificus in seafood, seawater and wastewater samples from a Mediterranean coastal area. Microbiol Res 165:657-664. https://doi.org/10.1016/j.micres.2009.11.012

Croci L, Suffredini E, Cozzi L, Toti L (2002) Effects of depuration of molluscs experimentally contaminated with Escherichia coli, Vibrio cholerae 01 and Vibrio parahaemolyticus. J Appl Microbiol 92:460-465. https://doi.org/10.1046/j.1365-2672.2002.01548.x.

Deeb R, Tufford D, Scott GI, Moore JG, Dow K (2018) Impact of climate change on Vibrio vulnificus abundance and exposure risk. Estuaries Coasts 41:2289-2303. https://doi.org/10.1007/s12237-018-04245 .

Duncan DB (1955) Multiple range and multiple F tests. Biometrics 11:1-42.

Farmer lii JJ, Michael Janda J, Brenner FW, Cameron DN, Birkhead KM (2015) Vibrio. Bergey's Manual of Systematics of Archaea and Bacteria, 1-79. https://doi.org/10.1002/9781118960608.gbm01078

Martins F, Reis MP, Neves R, Cravo AP, Brito A, Venâncio A (2006) Molluscan shellfish bacterial contamination in Ria Formosa coastal lagoon: a modelling approach. J Coast Res 1551-1555.

Gao X, Miao Z, Li X, Chen N, Gu W, Liu X, Yang H, Wei W, Zhang X (2019) Pathogenicity of non-01/0139 Vibrio cholerae and its induced immune response in Macrobrachium rosenbergii. Fish \& shellfish immunology, 92:300-307. https://doi.org/10.1016/j.fsi.2019.06.032. 
Gulig PA, Bourdage KL, Starks AM (2005) Molecular Pathogenesis of Vibrio vulnificus. J Microbio 43:118131. Retrieved from http://www.ncbi.nlm.nih.gov/pubmed/15765065

Gyawali P, Sidhu JP, Ahmed W, Jagals P, Toze S (2015) Rapid concentration and sensitive detection of hookworm ova from wastewater matrices using a real-time PCR method. Experimental parasitology 159:512. https://doi.org/10.1016/j.fsi.2019.06.032.

Han F, Wang F, Ge B (2011) Detecting Potentially Virulent Vibrio vulnificus Strains in Raw Oysters by Quantitative Loop-Mediated Isothermal Amplification. Appl Environ Microbiol 77(8), 2589-2595. https://doi.org/10.1128/aem.02992-10

Humphries RM, Linscott AJ (2015) Laboratory diagnosis of bacterial gastroenteritis. Clin Microbiol Rev 28:3-31. https://doi.org/10.1128/CMR.00073-14.

Jang YM, Park SK, Jeong HJ, Lee JW., Yoon Y, Park KS, Shin IS, Kim YM (2018) Quantitative Cell Count of Vibrio vulnificus Cells Based on MPN-PCR Method. J Food Hyg Saf 33:412-415. https://doi.org/10.13103/JFHS.2018.33.5.412.

Jiang F, Bi R, Deng L, Kang H, Gu B, Ma P (2018) Virulence-associated genes and molecular characteristics of non-01/non-0139 Vibrio cholerae isolated from hepatitis B cirrhosis patients in China. Int J Infect Dis 74:117-122. https://doi.org/10.1016/j.ijid.2018.06.021.

Jones MK, Oliver JD (2009) Vibrio vulnificus: disease and pathogenesis. Infect Immun 77:1723-1733. 10.1128/IAI.01046-08.

Khan F, Tabassum N, Anand R, Kim YM (2020) Motility of Vibrio spp.: regulation and controlling strategies. Appl Microbiol Biotechnol 1-22. https://doi.org/10.1007/s00253-020-10794-7

Kim HJ, Lee HJ, Lee KH, Cho JC (2012) Simultaneous detection of Pathogenic Vibrio species using multiplex real-time PCR. Food Control 23:491-498. https://doi.org/10.1016/j.foodcont.2011.08.019

Kwon JY, Song KC, Son KT, Yu H, Kim PH, Shin SB, Mok Js, Lee KJ, Oh EG, Yoon HD, Lim KS, Kim YM (2011) Development of a proficiency test specimen for enumerating Escherichiacoli in molluscan bivalve shellfish. Fish Aquatic Sci, 14:226-229. https://doi.org/10.5657/FAS.2011.0226

Lee R, Lovatelli A, Ababouch, L (2008) Bivalve depuration: fundamental and practical aspects. FAO. Retrieved from http://www.fao.org/3/a-i0201e.pdf

Levin RE (2004) The application of real-time PCR to food and agricultural systems. A review. Food Biotechnol 18:97-133. https://doi.org/10.1081/FBT-120030386.

Marino A, Lombardo L, Fiorentino C, Orlandella B, Monticelli L, Nostro A, Alonzo V (2005) Uptake of Escherichia coli, Vibrio cholerae non-ol and Enterococcus durans by, and depuration of mussels (Mytilus galloprovincialis). Int J Food Microbiol 99:281-286. https://doi.org/10.1016/j.ijfoodmicro.2004.09.003 
Nigro OD, Hou A, Vithanage G, Fujioka RS, Steward GF (2011) Temporal and spatial variability in culturable pathogenic Vibrio spp. in lake Pontchartrain, Louisiana, following Hurricanes Katrina and Rita. Applied and environmental microbiology, 77:5384-5393. 10.1128/AEM.02509-10.

Nyaruaba R, Mwaliko C, Kering KK, Wei H (2019) Droplet digital PCR applications in the tuberculosis world. Tuberculosis 117:85-92. https://doi.org/10.1016/j.tube.2019.07.001

Panicker G, Vickery MC, Bej AK (2004) Multiplex PCR detection of clinical and environmental strains of Vibrio vulnificus in shellfish. Can J Microbiol 50:911-922. https://doi.org/10.1139/w04-085

Panicker G, Call DR, Krug MJ, Bej AK (2004) Detection of pathogenic Vibrio spp. in shellfish by using multiplex PCR and DNA microarrays. Appl Environ Microbiol 70:7436-7444.

https://doi.org/10.1128/AEM.70.12.7436-7444.2004

Passalacqua PL, Zavatta E, Bignami G, Serraino A, Serratore P (2016) Occurrence of

Vibrioparahaemolyticus, Vibriocholerae and Vibriovulnificus in the clam RuditapesPhilippinarum (Adams \& Reeve, 1850) from Emilia Romagna and Sardinia, Italy. Ital J Food Saf 5:41-46. https://doi.org/10.4081/ijfs.2016.5709.

Qvarnstrom Y, James C, Xayavong M, Holloway BP, Visvesvara GS, Sriram R, Da Silva AJ (2005) Comparison of real-time PCR protocols for differential laboratory diagnosis of amebiasis. J Clin Microbiol, 43:5491-5497. https://doi.org/10.1128/JCM.43.11.5491-5497.2005.

Rivera ING, Chun J, Huq A, Sack RB, Colwell RR (2001) Genotypes Associated with Virulence in Environmental Isolates of Vibrio cholerae. Appl Environ Microbiol 67:2421-2429. https://doi.org/10.1128/AEM.67.6.2421-2429.2001

Rosec JP, Causse V, Cruz B, Rauzier J, Carnat L (2012) The international standard ISO/TS 21872-1 to study the occurence of total and pathogenic Vibrio parahaemolyticus and Vibrio cholerae in seafood: ITS improvement by use of a chromogenic medium and PCR. International journal of food microbiology, 157:189-194. https://doi.org/10.1016/j.ijfoodmicro.2012.04.026.

Schneider KR, Cevallos J, Rodrick GE (2009) Molluscan shellfish depuration. Shellfish Safety and Quality 509-541. https://doi.org/10.1533/9781845695576.5.509.

Shaw KS, Goldstein RER, He X, Jacobs JM, Crump BC, Sapkota AR (2014) Antimicrobial susceptibility of Vibrio vulnificus and Vibrio parahaemolyticus recovered from recreational and commercial areas of Chesapeake Bay and Maryland Coastal Bays. PLoS One 9:e89616. https://doi.org/10.1371/journal.pone.0089616.

Singh DV, Matte MH, Matte GR, Jiang S, Sabeena F, Shukla BN, Sanyal SC, Huq A, Colwell R R (2001) Molecular Analysis of Vibrio cholerae 01, 0139, non-01, and non-0139 Strains: Clonal Relationships between Clinical and Environmental Isolates. Appl Environ Microbiol 67:910-921.

https://doi.org/10.1128/AEM.67.2.910.

Page 22/28 
Starks AM, Schoeb TR, Tamplin ML, Parveen S, Doyle TJ, Bomeisl PE, Escudero MG, Gulig PA (2000) Pathogenesis of infection by clinical and environmental strains of Vibrio vulnificus in iron-dextran-treated mice. Infect Immun 68:5785-5793. https://doi.org/10.1128/IAl.68.10.5785-5793.2000

Stuart K, Rotman F, Drawbridge M (2016) Methods of microbial control in marine fish larval rearin: claybased turbidity and passive larval transfer. Aquaculture Research 47:2470-2480.

https://doi.org/10.1111/are.12696.

WHO. (2016). Cholera, 2015. Wkly Epidemiol Rec, 91(38), 433-440. Retrieved from http://www.ncbi.nlm.nih.gov/pubmed/27665620

WHO. (2017). Ending cholera a global roadmap to 2030. In Ending cholera a global roadmap to 2030. Retrieved from http://www.who.int/cholera/publications/global-roadmap.pdf?ua=1

Yokochi N, Tanaka S, Matsumoto K, Oishi H, Tashiro Y, Yoshikane Y, Nakashima M, Kanda K, Kobayashi G (2013) Distribution of Virulence Markers among Vibriovulnificus Isolates of Clinical and Environmental Origin and Regional Characteristics in Japan. PLoSOne 8:14-16.

https://doi.org/10.1371/journal.pone.0055219

Zavala-Norzagaray AA, Aguirre AA, Velazquez-Roman J, Flores-Villaseñor H, León-Sicairos N, Ley-Quiñonez CP, Hernández-Díaz LDJ, Canizalez-Roman A (2015) Isolation, characterization, and antibiotic resistance of Vibrio spp. in sea turtles from Northwestern Mexico. Frontiers in microbiology, 6:635. https://doi.org/10.3389/fmicb.2015.00635.

\section{Figures}




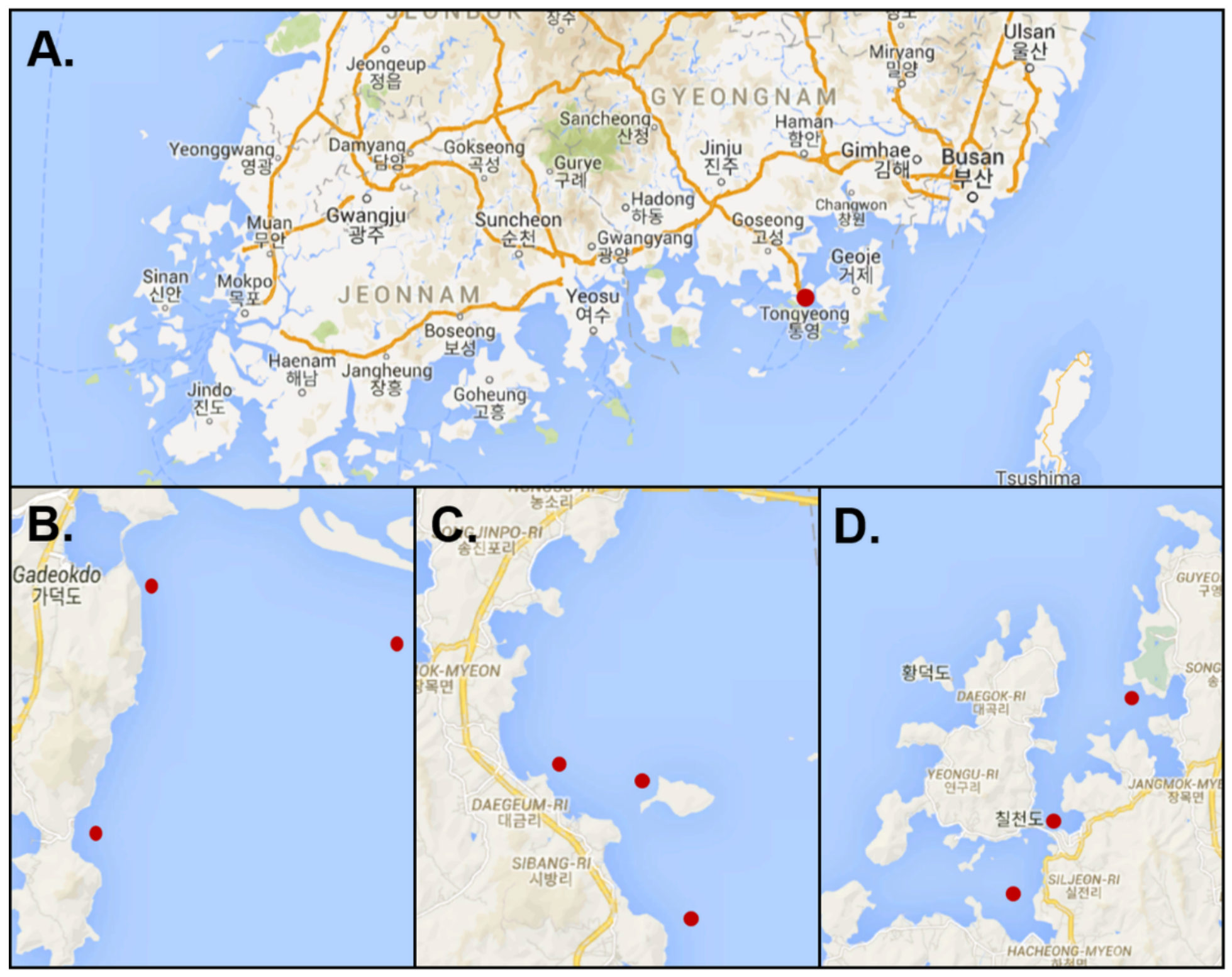

\section{Figure 1}

Sampling area of seafood and seawater in the Republic of Korea. (A) Tong young-city where local-market located. (B) Sampling points of seawater samples at the east coast of Gadeok Island. (C) Sampling points of seawater samples at the east coast of Geoje-city. (D) Sampling points of seawater samples at the coast of Chilcheon Island. Note: The designations employed and the presentation of the material on this map do not imply the expression of any opinion whatsoever on the part of Research Square concerning the legal status of any country, territory, city or area or of its authorities, or concerning the delimitation of its frontiers or boundaries. This map has been provided by the authors. 


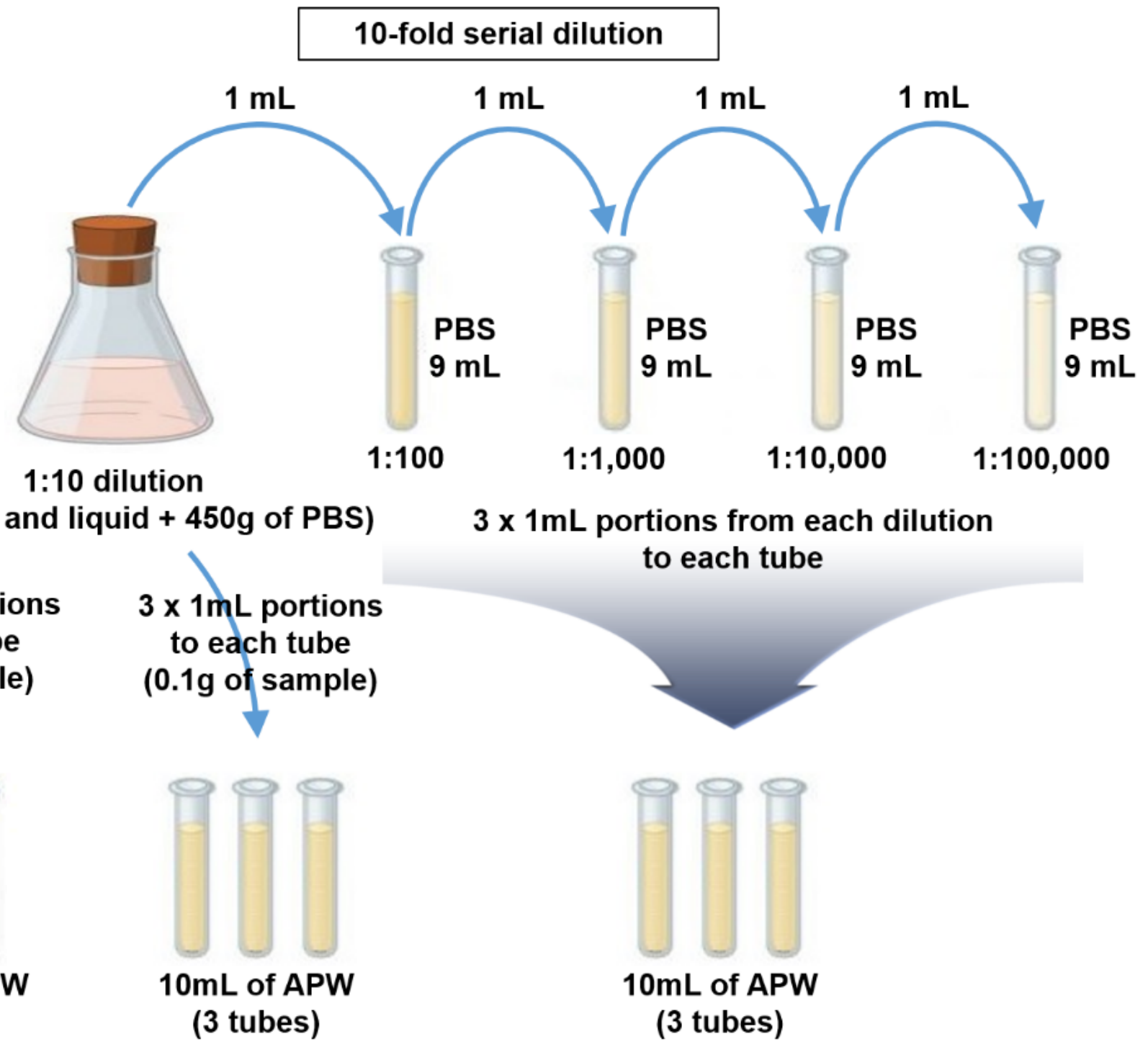

Figure 2

Schematic representation of the inoculate procedure for APW enrichment. 


\section{$3^{\text {rd }}$ Step}

1'Step

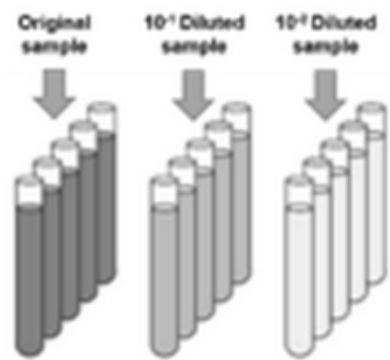

Incubation at $35^{\circ} \mathrm{C}, 14 \mathrm{hr}$ $\&$

Selection of test tubes with turbidity $2^{\text {nd }}$ Step

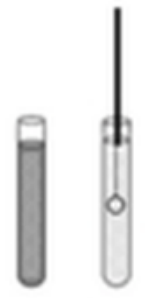

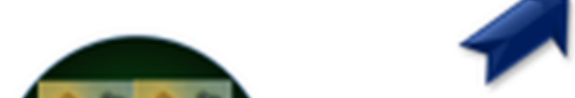

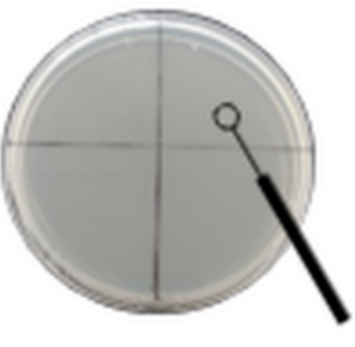

Picking yellow colony \& streak on LB-0 agar plate (Incubation at $35^{\circ} \mathrm{C}, 12-18 \mathrm{hr}$ )
Simple streak on TCBS agar plate $\&$ Incubation at $35^{\circ} \mathrm{C}, 12-18 \mathrm{hr}$

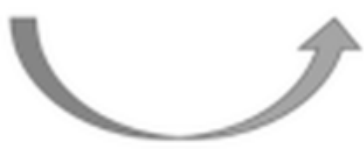

Picking green colony \& streak on

TCBS agar plate

(Incubation at $35^{\circ} \mathrm{C}, 12-18 \mathrm{hr}$ )

Figure 3

Schematic representation of the culture procedure before PCR.

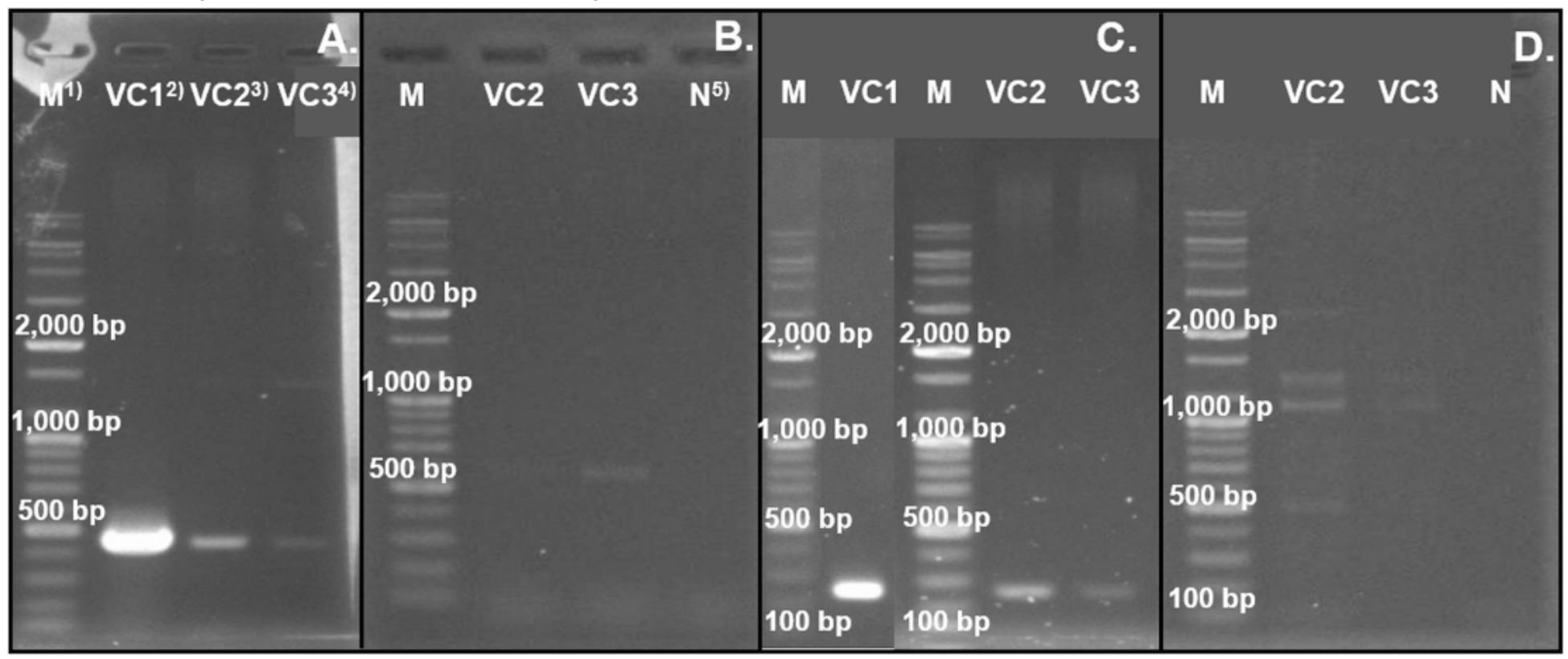

Figure 4 
Result of PCR with different tcpl and zot genes. (A) Result of PCR with tcpl gene-specific primer suggested by this study. (B) Result of PCR with tcpl gene-specific primer suggested by Singh et al. (2001). (C) Result of PCR with zot gene-specific primer was suggested by this study, and (D) Result of PCR with zot genespecific primer was suggested by Gao et al. (2019). Whereas, M; Marker. VC1; DNA of V. cholerae KCCM 41665. VC2; V. cholerae MFDS-2002810. VC3; Isolated V. cholerae (VCGS-1). N; Negative control.

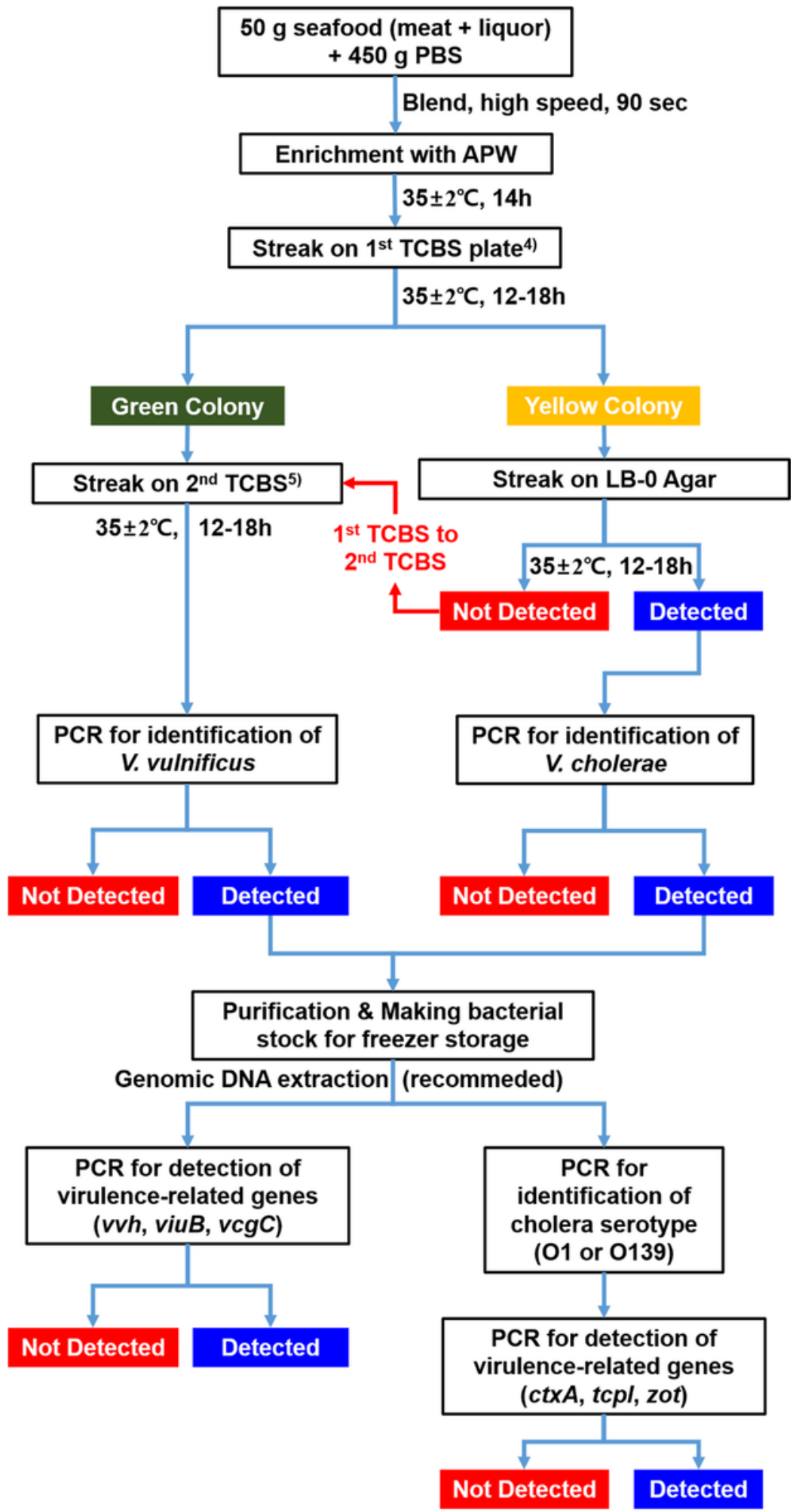

Figure 5 
The flow-chart showing the steps involved in the sample preparation, isolation, and quantification of Vibrio vulnificus and Vibrio cholerae colonies using the modified MPN-PCR method as suggested in this study. 